\title{
PICANTE A LA TACNEÑA
}

\author{
Picante a la tacneña
}

\section{Elard Vladimir Chaiña Flores ${ }^{1}$}

\begin{abstract}
RESUMEN
Como parte de un pequeño álbum de retratos fotográficos de ilustres tacneños en su mayoría, resaltan por su valor estético y etnográfico un par de retratos de damas, una indígena pelando papas y la otra una negra panadera, que sirven de pretexto para adentrarnos al arte culinario, especificamente al picante a la tacneña y su entorno.
\end{abstract}

Palabras clave: Ají, Picante a la tacneña, arte culinario, tarjeta de visita.

\section{ABSTRACT}

As part of a small album of photographic portraits of most illustrious Tacneños, a pair of portraits of ladies, an indigenous peeling potatoes and the other a black baker, stand out for their aesthetic and ethnographic value, serving as a pretext to delve into the culinary art specifically the picante a la tacneña and itsenvironment.

Keywords: Pepper, Picante a la tacneña, culinary Arts, visiting card.

\section{INTRODUCCIÓN}

La sentencia da cuenta de la gran variedad de picantes que uno puede degustar en el sur del Perú, ingredientes, sazones, sabores, porciones, calidades, entre otros; así mismo su amplia oferta denota su gusto popular por lo picante. El picante tacneño o a la tacneña permite adentrarnos en el ser de un pueblo; su historia, relaciones interculturales, valores culturales y definición de identidad.

\section{Tarjeta de visita}

Dos damas, una indígena pelando papas y una negra panadera, constituyen un valioso registro gráfico realizado por el fotógrafo Carlos E. Rodrigo, "El establecimiento fotográfico de retratos de Rodrigo fue sin duda el más popular y conocido de Tacna durante la segunda mitad del siglo XIX. Se inició utilizando el formato tarjeta visita, pero llegó a ocupar todos los formatos usuales de los grandes establecimientos en su género. Desde sus comienzos fue una sociedad entre Rodrigo y otros socios, posiblemente familiares, 1870/1875. El anuario Prado Martínez de 1903, 1904 y 1905 lo menciona como Rodrigo y Cía." (Hernán, 1985), el mismo que trabajó hasta la ocupación de Tacna.

La primera dama con pose forzada, como es usual en la fotografía del

\footnotetext{
${ }^{1}$ Doctor en Ciencias Sociales, Magíster en Arte, Licenciado en Arte. Docente de la Facultad de Ingeniería Civil, Arquitectura y Geotecnia. Universidad Nacional Jorge Basadre Grohmann. Tacna-Perú .

Correoelectrónico:ee012126@hotmail.com
} 


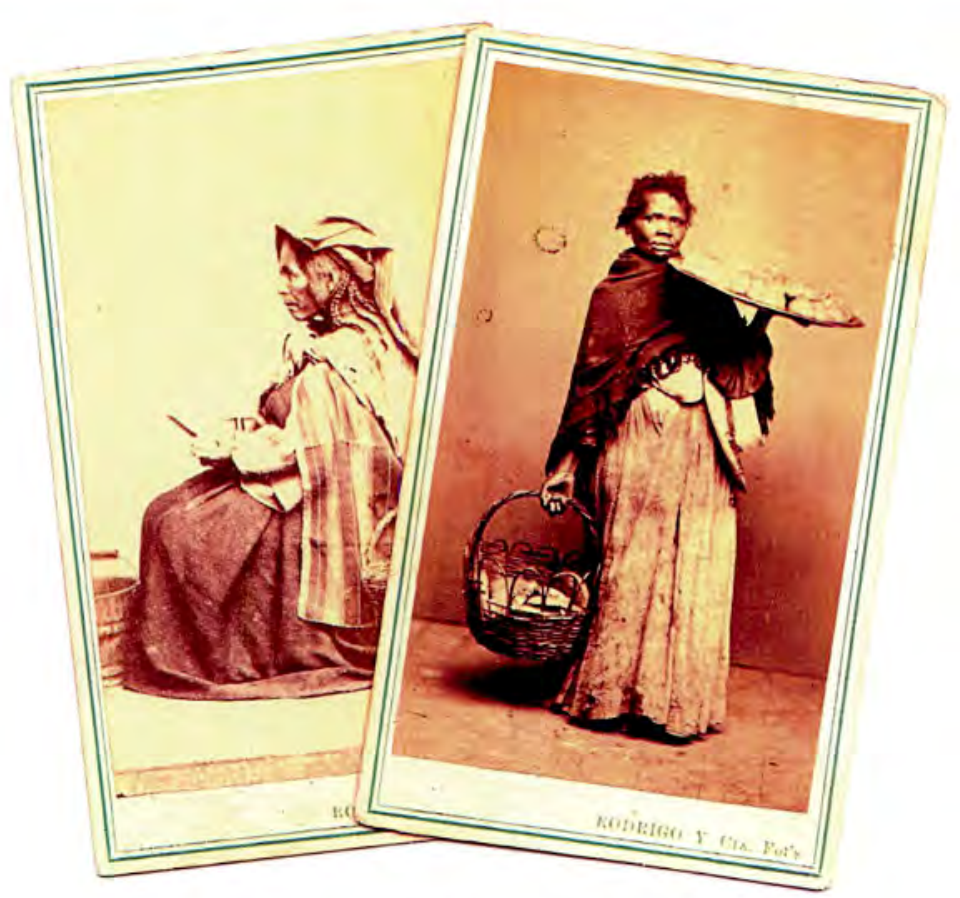

Figura 1. Indigena pelando papas - Negra panadera. Fuente: Colección del autor - Puno.

siglo XIX, donde "los indígenas son retratados usualmente como tipos etnográficos en las tarjetas de visita producidas en los estudios urbanos, en donde aparecen tan aislados del paisaje como de todo otro contexto" (Majluf, 2013); la dama sostiene con las manos un cuchillo y una papa; viste anaco, blusa con mangas anchas, faja o chumpi (no visible) frunciendo el anaco, phullo (con dobleces de guardado), lliclla y sobre varias trenzas un tocado cefálico o "manta" como es descrito por Enrique Tobar (1926) durante el cautiverio "en la plaza del mercado de Tacna, y observó que las vendedoras - peruanas, chilenas y de otras nacionalidades, pero en su gran mayoría peruanas - llevaban la "manta" antigua algunas, pocas el pañolón, y otras en fin, se hallaban "en talle" completamente descubiertas"; complementa y refuerza la estampa de indígena pelando papas, un canasto y una cuba de madera.

De manera más espontánea es presentada la negra panadera con faldón, chal y sombrero bajo el brazo, sostiene una bandeja con panes y una canasta llena de ellos.

Evidentemente las damas retratadas no pudieron acceder a costearse los retratos, la feliz iniciativa de Carlos E. Rodrigo, nos muestra la inseparable e histórica labor de la mujer que fue la preparación de alimentos como es el caso del picante a la tacneña, cuyo insumo es la papa y es acompañado del pan (tradicionalmente marraqueta).

\section{Ají, papas, charqui: intercambio entre pisos altitudinales \\ El álbum de retratos fotográficos de la cual son parte las dos fotografías aquí presentadas, fueron posesión del abogado y hacendado puneño, Dr. Fede- rico Antonio Morales, con vínculos fami-}


liares y comerciales con Tacna; indudablemente las fotografías también dan cuenta del fluido intercambio económico, social y cultura entre el altiplano y los valles costeros. Ya desde la visita hecha a la provincia de Chucuito en 1567 por Garci Diez de San Miguel, permite esclarecer junto con otras investigaciones que "Los Lupaca tenían oasis en la costa del pacifico - desde el valle de Lluta, en Arica [...] hasta Sama y Moquegua" (Murra, 1975), como tácticas complementarias por medio de movimientos espaciales de intercambio de bienes agrícolas principalmente, donde se enviaban "indios a rescatar a la costa y llevan para ello ganado, lana, ropa y carne seca, traen en rescate de ello maíz, ají, algodón, pescado seco y otras cosas"(Diez de San Miguel, 1964), los mismos que "convivían con una población costera o yunga hablante de la lengua puquina" (Choque \& Pizarro, 2009), denominada Colesuyo. Enclaves que "Murra llama "archipiélago" o el "control vertical de un máximo de pisos ecológicos", y que descansa en la necesidad de operar zonas productivas variadas y situadas a muy diferentes niveles sobre el mar" (Pease, 1975).

Uno de los muy apreciados productos de estos valles fue el ají, palabra introducida desde Caribe; en quechua "Vchú. El común agi" (Gonzales Holgin, 1989); y en aimara Wayk'a o como lo registra Ludovico (1956) "Agi: Huayka" y una amplia descripción de su variedades; además fue un producto muy valorado como lo menciona Garci Diez de San Miguel (1964), la "chácara de ají que de una postura dura tres años y vale mucho" y es así que el establecimiento de "los mitmaq altiplánicos en los valles [...] tuvo como propósito el cultivo de maíz y ají, así como la recolección de algas marinas como el cochayuyo [...] lo que generó un periodo de coexistencia conflictiva entre los coles y las colonias lupaqa" (Choque \& Pizarro, 2009).

El entendimiento de las relaciones interculturales Lupaca, se amplió extraordinariamente al publicarse en 1964 la vista, y el control vertical planteado por Murra (1975), amplían el entendimiento del intercambio de bienes. La adaptación al clima hostil del altiplano permitió al poblador andino el cultivo principalmente de la Papa y la crianza de camélidos. "las papas [con] sus centenares de variedades, eran la principal cosecha de altura" (Murra, 1989) y al describir a los pobladores del Qollasuyo, Guaman Poma (1936) menciona que "tienen muy poca fuerza y ánimo y gran cuerpo y gordo seboso para poco porque comen todo chuño y ueuen chicha de chuño [...]". Las papas, el chuño sumado a los productos derivados de los auquénidos se convirtieron en los principales producto de intercambio con los valles sujetos al altiplano, "Esos asentamientos trasplantados permanecían bajo la jurisdicción de su curaca tradicional y les proporcionaban a sus parientes maíz, ají, frutas y otros productos [...] a cambio de llamas, charqui y chuñu" (Murra, 1989), intercambio comercial que continuo durante todo el periodo colonial (Glave, 1989), y republicano (Flores Ochoa, 1977), incluso "las creencias actuales de los moradores del altiplano boliviano que consideran que sus muertos van todavía a plantar ají en las tierras del pacífico" (Bouvsse-Cassagne, 1988).

El ají constituyó uno de los principales productos del valle de Tacna, ingrediente principal del picante a la tacneña.

\section{Ají, menudencias, papas: estigma de marginalidad.}

La mesa peruana o sea el libro de las familias, fue el primer libro de cocina peruana, escrito y publicado en Arequi- 
pa en 1867, sobre los picantes menciona que "propiamente podíamos llamar platos de antojo, por cuanto se toman extraordinariamente en ciertos días festivos y de expansión para beber un vaso de chicha en el seno de la familia y de la intimidad" (anónimo, 1867), y es en la intimidad que "era degustada también por las clases acomodadas en privado, públicamente se prefería alabar la cocción francesa. Ni que decir de comer con ají, algo que por entonces los atildados cronistas de la aristocracia [...] censuraban como "costumbre de salvajes" (Sánchez, 2009).

Las menudencias también será "considerada un alimento inferior por la dieta europea, [pero que] podía tener gran aceptación en tierras del Perú, debido a la antigua costumbre alimenticia de la Península Ibérica" (Varella, 2009), considerada por los indígenas como un regalo al paladar, bajo la licencia de consumo en días de la semana prescritos por la iglesia para la abstinencia de carne, como los sábados "a partir del año 762 y por un acuerdo entre Rey y el papa Paulo I, en toda España se dio principio a una costumbre que se conservó en los antiguos reinos de León y Castilla, así como en las regiones bajo su influencia: el día sábado se comía tocino, grasa, cabeza, pulmones, corazón, hígado, callos (mondongo), riñones" (Olivas, 1998).

Sobre el consumo de papas, Guaman Poma (1936) sugiere que fue un signo de status bajo; Francisco de Avila, en "el mito de Huatyacuri (cuyo nombre significa papa asada debido a que eso era lo que comía por su condición de pobreza" (Ossio, 1993), y bajo ese concepto en sus inicios su consumo fue marginal en Europa.

Comer ají, menudencias, y papas le crearon un estigma marginal al picante a la tacneña, pero antes de su actual conformación culinaria debió recrear el picante (plato) algo del intercambio de bienes con el altiplano, como los derivados de los auquénidos como el charqui y las papas. Como lo sugieren Olivas (1993) y Alvarez (1993), los cuales citando a Bertonio, basados en los términos Calapurcca, o Cala Phurcatha, Cozer afsi echando en la olla las piedras calientes donde efta la carne, como forma de cocción muy peculiar que por el nombre se vincularía con la actual Carapulca o carapulcra que no es más que un picante con papas cocidas y secadas.

\section{El picante a la tacneña}

Uno de los emblemáticos establecimientos en Tacna es el restaurante "La casa del Picante" dirigida por Ida Supo de Ticona nuera de Yolanda Franco Vda. de Ticona, cuya receta tradicional fue difundida por "Gustos y Sabores" programa emitido por TV Perú en el 2001, conducido por Roberto Wong, a cuya preparación nos ceñimos:

\section{Picante a la tacneña (Para 6 personas)}

50 gr. de ají rojo seco (negro o panca).

25 gr. de ají amarillo seco (mirasol)

25 gr. de ají limeño (o rojo seco).

2 kilos de papa Mariva.

100 gr. de charqui (carne seca de res).

100 gr. de chalona (carne seca de cordero).

100 gr. de mondongo.

Orégano, comino, ajos y sal al gusto.

\section{Preparación.}

A. Preparación previa de los ajíes.

\section{Secar el ají.}

Remojar el aji, (rojo, negro y amarillo), limpiar, licuar con ajo y cebolla. Llevar al fogón hasta coser el ají, agregar comino y orégano molido, sal al gusto, a este proceso se llama secar el ají, hasta que esté cocido. 


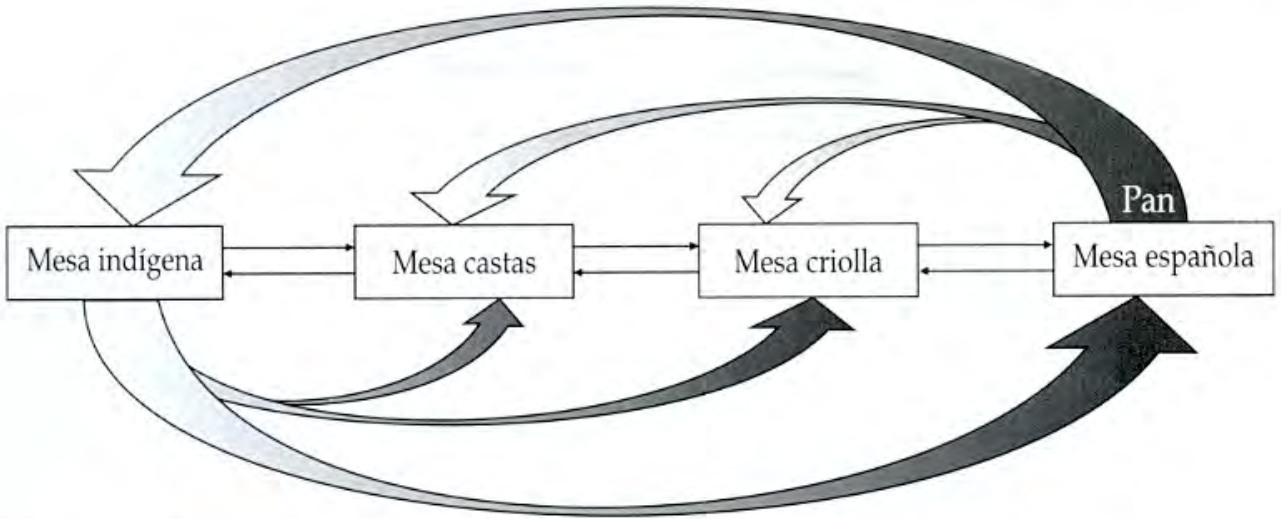

Figura 2. Ají y pan - productos emblemáticos de castas coloniales. Fuente: Amodio (2014).

\section{2 "Quemar" el ají.}

Agregar el aceite para que "queme", a esta otra etapa de la preparación se le denomina "quemar el aji" y a la capa de grasa que cubre el ajíse denomina "tez".

B. Elaboración del picante a la tacneña.

Calentar en una olla de barro el ají procesado, agregar la chalona de cordero, orégano, caldo de mondongo, patas, carnes, charqui y patas de res y mondongos picados. Finalmente agregar la papa mariva cosida y estrujada. A la hora de servir acompañar con marraqueta.

Sobre la marraqueta que acompaña el picante, Juan Paulo Canepa, Cónsul Italiano en Tacna, menciona "aquí antiguamente casi todas las panaderías eran italianas, hacían [...] un pan que se llama marraqueta que no hacen en otra parte. Había dos grandes panaderías de los hermanos Rocchetti que eran italianos [...]" (Gustos y Sabores, 2011), elemento que se integra al picante como un "fenómeno de "fosilización de la cultura", típicos de los procesos migratorios. Es que los migrantes conservan elementos de su cultura de origen" (Bonfiglio, 1993), y la integran a la cultura originaria.

\section{A MANERA DECONCLUSIÓN}

Para muchos, nacido como un plato marginal, por sus humildes orígenes ligados al pueblo y a la utilización de menudencias. El plato está ligado principalmente a la producción del ají ingrediente de alma de local. Comer ají es, al mismo tiempo sufrir y gozar, es la sublime relación entre sufrimiento y placer. El ají es la expresión del proceso histórico de Tacna, que ha recibido diversos aportes culinarios de orígenes andinos, hispanos, italianos, entre otros.

Hoy el picante constituye un emblema de identidad, historia, relaciones interculturales, participación femenina y valores culturales como por ejemplo después de un sepelio el picante tiene una función simbólica, comprendida y aceptada por su colectividad.

\section{REFERENCIAS BIBLIOGRÁFICAS}

Amodio, E. (2014). La mesa pintada intercambio de productos alimentarios entre Europa y América y sus representaciones en la pintura barroca latinoamericana. En: Migraciones \& Rutas del Barroco VII Encuentro Internacional sobre el 
barroco. La Paz, Bolivia: Fundación Visión Cultural.

Anónimo. (1867). La mesa peruana o sea el libro de las familias. Arequipa, Perú: Editor Francisco Ibáñez.

Alvarez Novoa, I. (1993). La cocina criolla. En Cultura, identidad y cocina en el Perú. Lima, Perú: USMP.

Bertonio, L. (1956) [1612] - Vocabulario de la lengua aymara. La Paz, Bolivia: Litografía Don Bosco.

Bonfiglio, G. (1993). La influencia italiana en la cultura culinaria peruana. En Cultura, identidad y cocina en el Perú. Lima, Perú: USMP.

Bouysse-Cassagne, Th. (1988). Lluvias y cenizas - Dos Pachacuti en la Historia. La Paz, Bolivia: Hisbol.

Choque, C. \& Pizarro, E. (2009). El Colesuyo meridional: espacio de articulación económica y cultural hispano-indígena en la segunda mitad del siglo XVI. en: Allpanchis Año XI., No 73/74. Lima, Perú: Editorial del Instituto de Pastoral Andina

Diez de San Miguel, G. (1964) [1567]. Visita hecha a la provincia de Chucuito por Garci Diez de San Miguel en el año 1567 - Documentos regionales para la etnología y etnohistoria andinas, $\mathrm{N}^{\circ} \mathrm{I}$. Lima, Perú: Editorial Casa de la Cultura del Perú.

Flores Ochoa, J. A. (1977). Pastores de Puna-Uywaminchiq Punarunkuna. Lima, Perú: IEP.

Glave, L. M. (1989). Trajinantes - Caminos indigenas en la sociedad colonial siglos XVI/XVII. Lima, Perú: Instituto de Apoyo Agrario.

Gonzalez Holguin, D. (1989) [1608]. Vocabulario de la lengua general de todo el Perú llamada lengua qquichua o del inca. Lima, Perú: Universidad Nacional Mayor de San Marcos. Guaman Poma, P. (1936) [1615]. El primer nueva coronica y buen gobierno. Paris: Edición facsimilar. Institut d'Etnologie.

Majluf, N. (2013). Rastros de un paisaje ausente: fotografía y cultura visual en el área andina. En Caiana, revista de historia del arte y cultura visual del centro argentino de investigadores de arte (CAIA), $N^{\circ} 3$.

Murra, J. (1975). Formaciones económicas y políticas en el mundo andino. Lima, Perú: IEP.

Murra, J. (1989). La organización económica del estado inca. Quinta edición. D.F. México: Siglo Veintiuno.

Olivas, R. (1993). Los dulces tradicionales del Perú. En Cultura, identidad y cocinaenel Perú. Lima, Perú:USMP.

Olivas, R. (1998). La cocina en el virreinato del Perú $\left(2^{\circ}\right.$ Ed.). Lima, Perú: Universidad de San Martín de Porres.

Ossio, J. (1993). Aspectos simbólicos de las comidas andinas. En Cultura, identidad y cocina en el Perú. Lima, Perú: USMP.

Pease, F. (1975). Prologo. En Formaciones económicas y políticas en el mundo andino. Lima, Perú: IEP.

Rodríguez Villegas, H. (1985). Historia de la Fotografia en Chile - Registro de daguerrotipistas, fotógrafos, reporteros gráficos y camarógrafos 1840 1940. En Boletín de la Academia Chilena de la Historia. Año LII, $\mathrm{N}^{\circ}$ 96. Santiago de Chile.

Sánchez, E. (2009). Historias de mantel largo. En Revista Somos. Año XXII $\mathrm{N}^{\circ}$ 1190. El Comercio S.A.

Tovar, E. (1926). Raza chilena - a través de la sociología y de la historia de chile. Lima, Perú: La opinión nacional.

Varella, A. (2009). Dulces regalos del Nuevo Mundo - Alimentos de indios en las recetas medicinales del padre Bernabé Cobo (S. XVII). en: Allpanchis Año XI, No 73/74. Lima, Perú Instituto de Pastoral Andina. 